\title{
A Novel Surgical Template Design in Staged Dental Implant Rehabilitations
}

\author{
Michael Patras' ${ }^{1}$ William Martin ${ }^{1}$, Nikitas Sykaras² \\ ${ }^{1}$ Department of Oral and Maxillofacial Surgery, Center for Implant Dentistry, University of Florida, Gainesville, Florida, \\ USA. \\ ${ }^{2}$ Department of Prosthodontics, University of Athens, Athens, Greece.
}

\author{
Corresponding Author: \\ Nikitas Sykaras \\ 25 Nikis str., GR - 15233, Halandri \\ Greece \\ Phone: +30 2106800636 \\ Fax: +30 2107236051 \\ E-mail: nsykaras@otenet.gr
}

\begin{abstract}
Background: The philosophy of a gradual transition to an implant retained prosthesis in cases of full-mouth or extensive rehabilitation usually involves a staged treatment concept. In this therapeutic approach, the placement of implants may sometimes be divided into phases. During a subsequent surgical phase of treatment, the pre-existing implants can serve as anchors for the surgical template. Those modified surgical templates help in the precise transferring of restorative information into the surgical field and guide the optimal three-dimensional implant positioning.

Methods: This article highlights the rationale of implant-retained surgical templates and illustrates them through the presentation of two clinical cases. The templates are duplicates of the provisional restorations and are secured to the existing implants through the utilization of implant mounts.

Results: This template design in such staged procedures provided stability in the surgical field and enhanced the accuracy in implant positioning based upon the planned restoration, thus ensuring predictable treatment outcomes.

Conclusions: Successful rehabilitation lies in the correct sequence of surgical and prosthetic procedures. Whenever a staged approach of implant placement is planned, the clinician can effectively use the initially placed implants as anchors for the surgical template during the second phase of implant surgery.
\end{abstract}

Keywords: implantation, dental; dental implant; implant-supported dental prosthesis; dental restoration, temporary.

Accepted for publication: 22 May 2012.

To cite this article:

Patras M, Martin W, Sykaras N. A Novel Surgical Template Design in Staged Dental Implant Rehabilitations.

J Oral Maxillofac Res 2012 (Apr-Jun);3(2):e5

URL: http://www.ejomr.org/JOMR/archives/2012/2/e5/v3n2e5ht.pdf

doi: 10.5037/jomr.2012.3205 


\section{INTRODUCTION}

Recent advances in implant dentistry have introduced a number of alternative treatment options for the rehabilitation of partially and completely edentulous patients $[1,2]$. In recent years, focus has shifted to a great extent into the restoration-driven approach for the placement of dental implants through a detailed presurgical planning [ [3]. However, functional and aesthetic replacement of multiple missing teeth with implantsupported restorations remains a complex task and requires a comprehensive treatment planning.

Traditionally, in clinical situations where a patient presented with advanced periodontal and/or structural problems to the teeth, the treatment of choice often involved approaches that focused on extraction of remaining teeth, followed by hard and soft-tissue regeneration procedures prior to the placement of the dental implants. These rehabilitations often required a significant amount of healing time utilizing delayed loading protocols and removable interim restorations during the transitional period. For many patients this treatment approach was not attractive due to the consequent impact of an interim removable prosthesis on psychology, phonetics and mastication. For all the aforementioned reasons, as well as in cases of patients with thin gingival biotype, in need of extensive surgeries or in clinical cases where immediate loading is contraindicated, the clinician is forced to suggest a smoother transition into the fixed implant restorations []].

This procedure involves serial extraction of selected hopeless teeth and the placement of implants and/or grafts through a staged approach while utilizing the remaining teeth to support a fixed interim restoration [5]. An important parameter in this therapeutic approach is the preservation of natural teeth, whether of fair or questionable prognosis until the end of the healing process. Upon successful osseointegration of the first series of implants, the tooth-supported interim restoration is converted to an implant-supported provisional prosthesis. This procedure allows for the extraction of the remaining hopeless dentition and subsequent progression to the second phase of implant rehabilitation [ $\underline{5}$.

In preparation for the surgery, the duplication of the provisional prosthesis facilitates the fabrication of a surgical template that will dictate the location and inclination of the additional implants [6-9]. To achieve optimal accuracy and effectiveness, the surgical template should be simple in construction, have sufficient stability and not interfere with the surgeon's access $[\underline{8}, \underline{10}]$.
A variety of surgical templates differing in design, cost, and stability have been described in the literature. They are usually made of thermoplastic sheets or clear acrylic resin $[9,11-14]$. In partially edentulous patients, they cover the occlusal surfaces of the adjacent teeth or rest on any prepared teeth to gain adequate retention and support [15]. On the contrary, when templates are derived from a duplication of transitional removable prostheses, their precise repositioning is extremely difficult after tissue reflection because of a change in the architecture of the underlying soft tissues that served as the only reference points [15-16].

Serving as the communication tool for transferring to the surgeon the necessary guidelines for implant placement, it is quite clear that a stable, well-designed surgical template can improve the accuracy of the surgical implant installation, thus reducing the duration of surgery $[\underline{8}, 21-23]$. Even though several techniques have been reported in the literature for surgical template stabilization in the form of surgical fixation screws [17], transitional implants $[16, \underline{18}-$ 19], or sequential extraction of the remaining teeth during implant placement [20], those solutions seem to be rather complicated. Therefore, whenever a staged rehabilitation is planned, the clinician can effectively use the existing implants as anchors for the surgical template during the second phase of implant surgery. The objective of this paper is to describe the utilization of previously used implant mounts for the fabrication of stable surgical templates in such staged procedures. The rationale and design of fixed surgical templates is illustrated through the presentation of two clinical cases.

\section{CASES DESCRIPTION AND RESULTS}

\section{Case 1}

A 66-year old patient presented to the clinic with extensive restorations in both arches. The clinical and radiographic examination revealed caries under the existing restorations combined with generalized moderate to severe bone loss due to periodontitis. After the fabrication of diagnostic casts, a wax-up was performed in accordance with the aesthetic and functional requirements of the case. Given the severity of dental caries and extensive bone loss, the treatment plan advocated for the extraction of the majority of the maxillary teeth. Furthermore, the diagnostic waxup confirmed a hard-tissue deficit in bucco-lingual dimension resulting in insufficient ridge width for ideal implant positioning in the anterior maxilla. Since the patient declined the use of immediate dentures, a two-stage approach for the extractions and implant 
placement was planned. After laboratory fabrication of the provisional restorations, all existing restorations were removed. The extraction of several hopeless teeth was performed with emphasis on retaining as many abutments as possible, in a satisfactory antero-posterior distribution and in strategic locations on the maxillary arch. The provisional restoration was relined, cemented with provisional cement and served for the evaluation of aesthetic and functional characteristics.

Following patient's consent, the duplication of the interim prosthesis facilitated the construction of a tooth-supported combined radiographic-surgical template. The first phase of surgery included the placement of bone grafts in the anterior region and four implants at the first premolar and molar sites in the maxilla. After a period of six-months and complete healing of the graft sites, the interim restoration was removed and an implant level impression was made, followed by the construction of a master cast (Figure 1). Additionally, temporary abutments were placed intraorally and the interim restoration was converted into an implant-supported restoration. Upon delivery of the interim implant-supported restoration, a new alginate impression was made.

In the laboratory, a vacuform matrix (Invisacryl A,

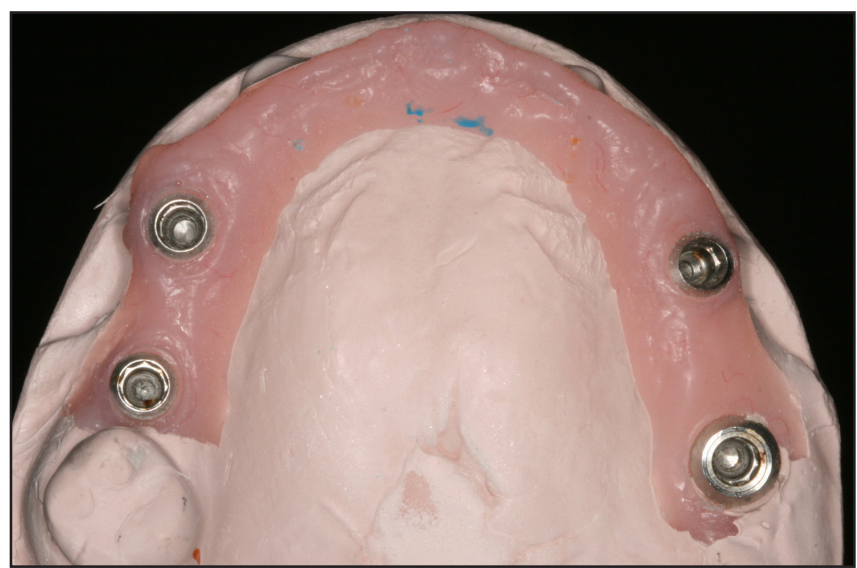

Figure 1. Master cast with implant analogs in place.
Great Lakes Orthodontics LTD, NY, USA) was made over the new diagnostic cast. Two implant mounts (Straumann USA, Andover, MA, USA) were placed on the premolar analogs (Straumann USA, Andover, MA, USA), and the cast was coated with a liquid separator. Two holes were drilled in the vacuform matrix to allow it to be properly seated over the implant mounts. The vacuform matrix was then filled with clear, auto-polymerizing acrylic resin (Orthodontic Resin, Dentsply Caulk, Milford DE, USA), carefully placed in the cast and secured with rubber bands (Figure 2). The acrylic resin was allowed to set in a pressure pot for ten minutes at which point it was removed and the excess material was trimmed and polished (Figure $3 \mathrm{~A}$ and $3 \mathrm{~B}$ ). During the second surgery the surgical template was screw retained to the existing implants after tissue reflection (Figure 4). Maintaining teeth contours in the surgical template enabled the surgeon to visualize the proposed implant positions based upon the ideally planned restorative positions.

\section{Case 2}

During the course of treatment, the implant in site \#33 was lost due to peri-implantitis. A master cast

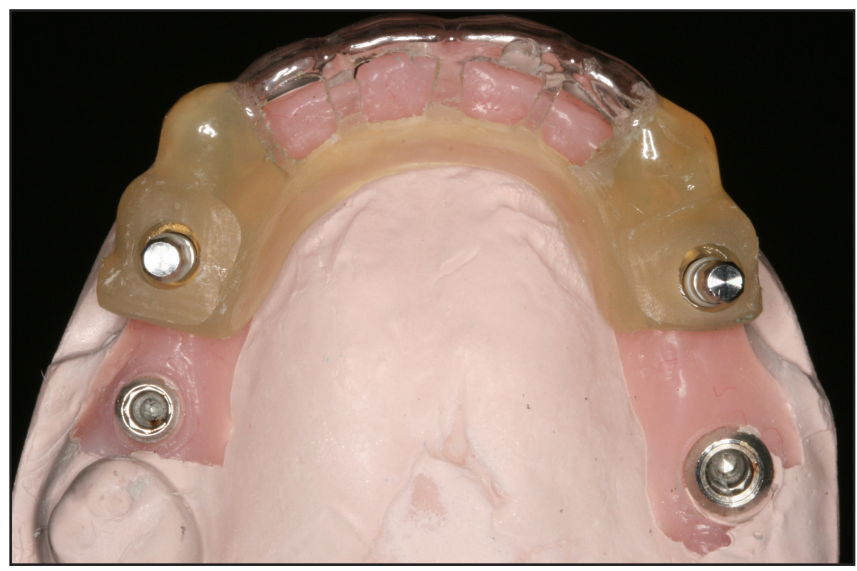

Figure 2. Vacuform template relined over implant mounts.

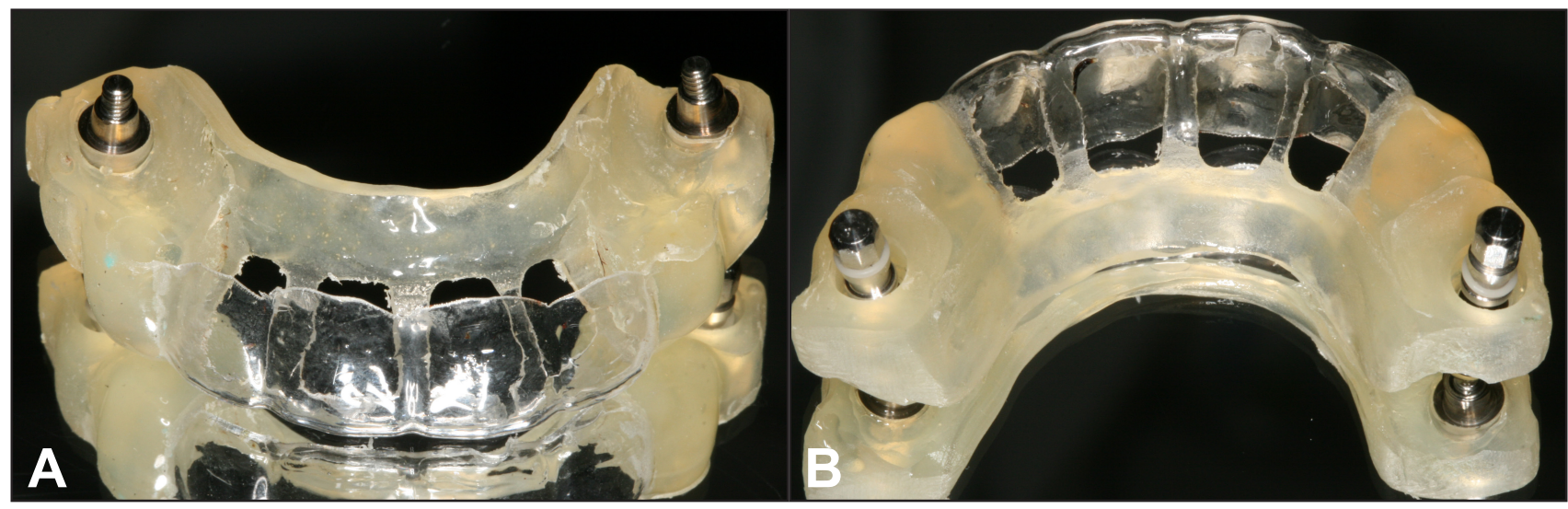

Figure 3. $\mathrm{A}=$ intaglio view of the template after polishing; $\mathrm{B}=$ cameo view of the template after polishing 


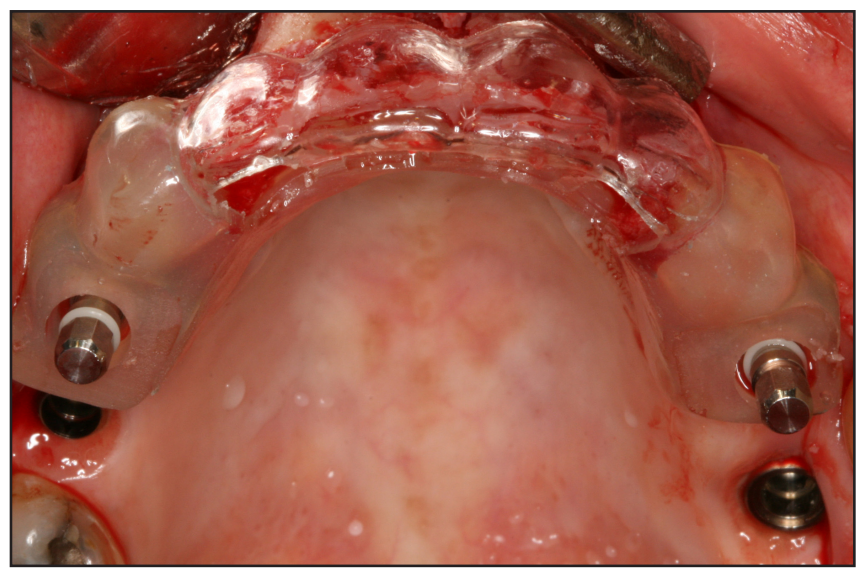

Figure 4. Template retained on implants prior to implant positioning.

was made of the remaining three implants in sites \#36, \#43 and \#46 (Figure 5). A vacuform matrix (Invisacryl A, Great Lakes Orthodontics LTD, NY, USA) fabricated from the original wax-up was relined over two implant mounts (Straumann USA, Andover, MA, USA) on implant analogs at sites \#36 and \#43 utilizing clear, auto-polymerizing acrylic resin (Orthodontic Resin, Dentsply Caulk, Milford DE, USA) (Figure 6). The template was trimmed, polished and sterilized prior to surgery (Figures 7A and 7B). At the surgical visit, once the tissue was reflected at site $\# 33$, the template was placed onto implants \#36 and \#43 and provided a clear visualization of the desired implant position based upon the planned restoration (Figure 8).

\section{DISCUSSION}

Fixed provisional prostheses are preferred by most patients because of their improved aesthetics, stability and ease of use. Preserving teeth with poor or questionable prognosis to support a fixed provisional restoration helps to avoid excessive loading of the grafted sites and ensures an uneventful healing process. Furthermore, both the patient and the clinician may

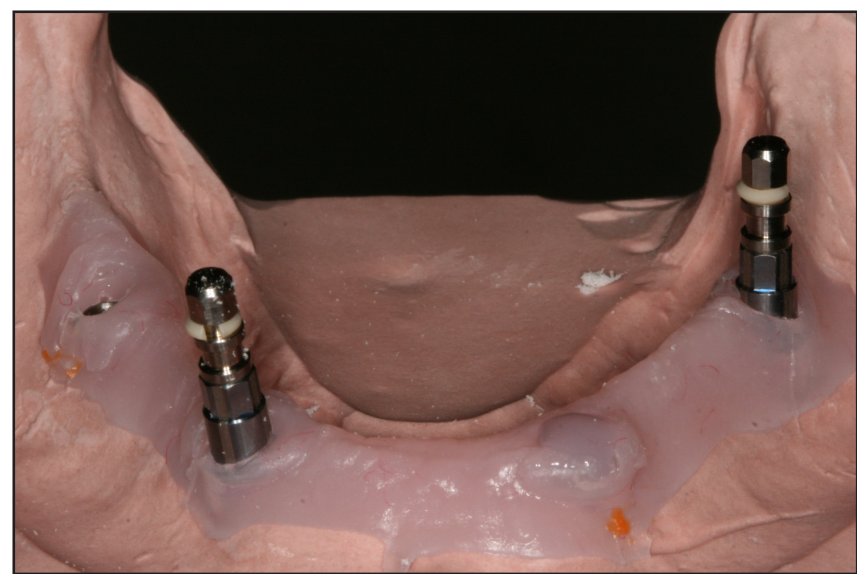

Figure 5. Master cast with implant mounts in place.

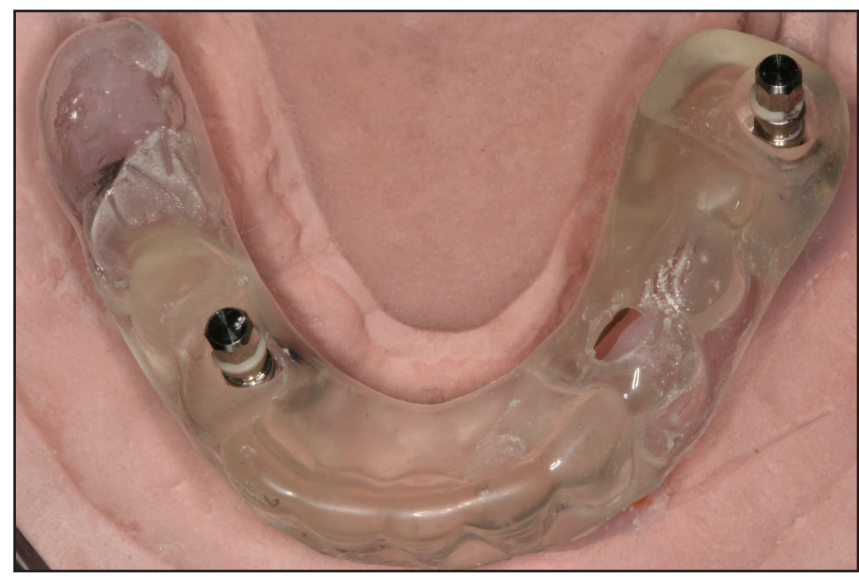

Figure 6. Vacuform template relined over implant mounts.

avoid the additional appointments that are necessary for subsequent relines and any other modifications needed in case of interim removable prostheses [5] .

This paper describes the use of a surgical template design that allows precise implant installation in two stages. Initial implant placement includes the use of a surgical guide that is tooth-supported, whereas second phase implant surgery utilizes an implant-supported one. This template may also resemble the diagnostic waxup or the provisional restoration, thus giving similar

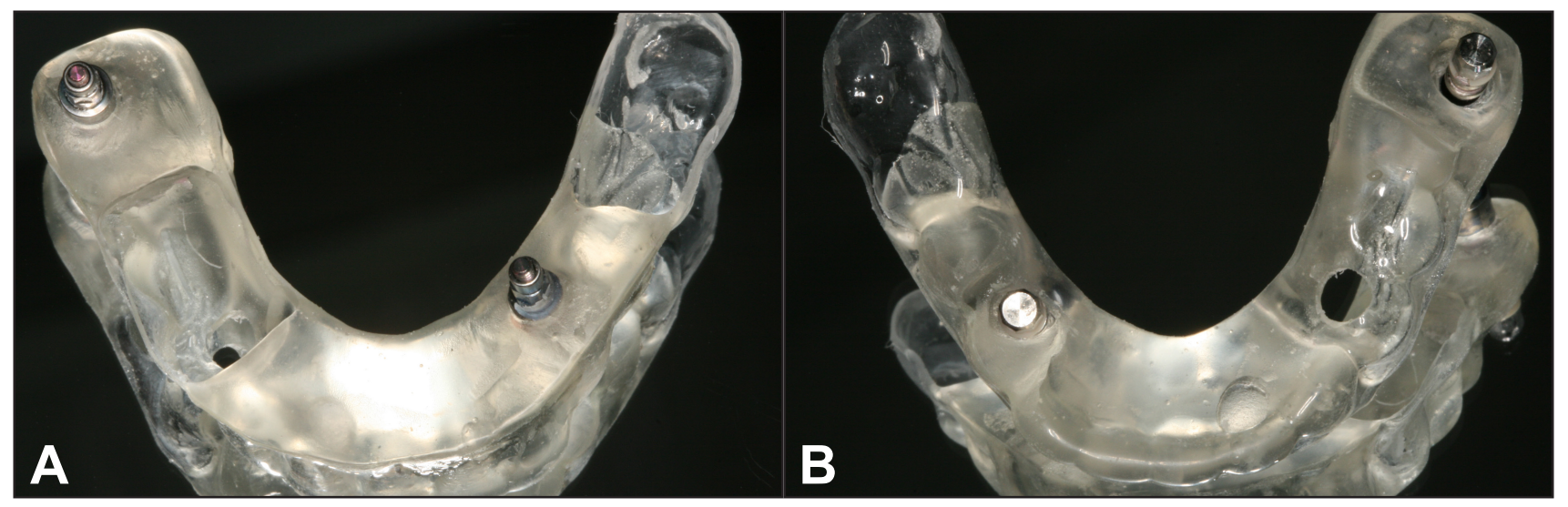

Figure 7. $\mathrm{A}=$ intaglio view of the template after polishing; $\mathrm{B}=$ cameo view of the template after polishing. 


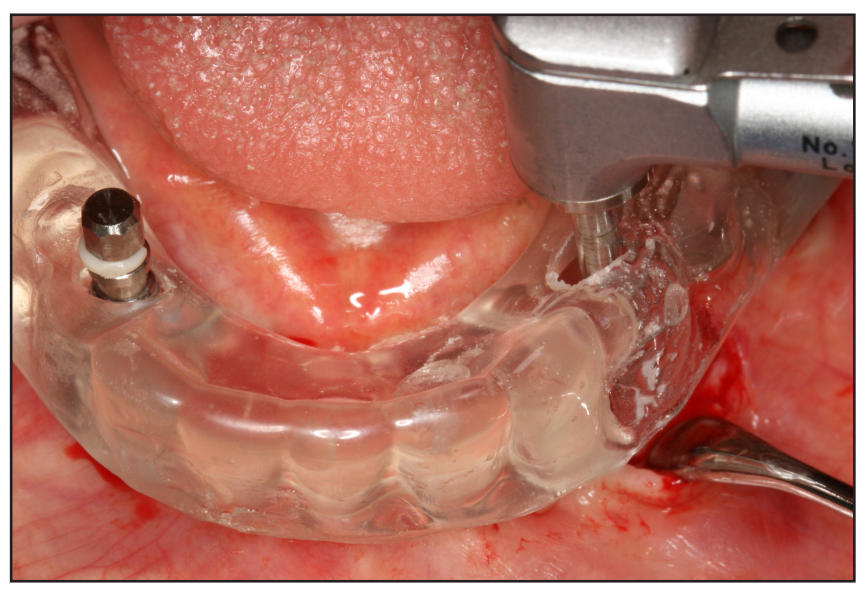

Figure 8. Template retained on implants prior to implant positioning.

accuracy and helping to achieve a satisfactory final result. Other advantages include ease of manufacture and low cost, while using materials, techniques and equipment that are usually available in the office or lab. The incorporation of stable anchoring elements into the template presented herein, allows its use in multiple ways. The master cast containing the first phase implant analogs can be used to fabricate the final provisional restoration. When additional implants are installed, this pre-fabricated provisional restoration can be modified to take advantage of the additional support and provide immediate loading if needed. After the necessary time for osseointegration has elapsed and the restorative phase commences, this surgical template can be further modified to a registration template to help the clinician fast and accurately mount the final working cast in the articulator.

Alternative retention devices (other than implant mounts) can be utilized such as positioning indicators (Straumann USA, Andover, MA, USA) (Figure 9) or impression components. Their stability and design allow for unrestricted tissue reflection, adequate irrigation of the region and enhance the predictability of the implant position and inclination and therefore preventing the injury of adjacent anatomical structures (teeth, sinus, mandibular canal) [9]. In addition to the corresponding accuracy due to the existence of reference points (restoration contours, cervical outline), the surgical procedure is also accelerated, with a positive impact on the post-operative healing. Also, the parts used for the anchoring of surgical guides provide reference points for the inclination of the previously placed implants. Finally, they assist in the uncovering procedure as they indicate the positions of implantation, thus contributing to a less traumatic procedure. The only drawbacks to this technique are the additional laboratory time required for the fabrication of a new template and the necessary construction of a new final working cast at the completion of the healing phase.

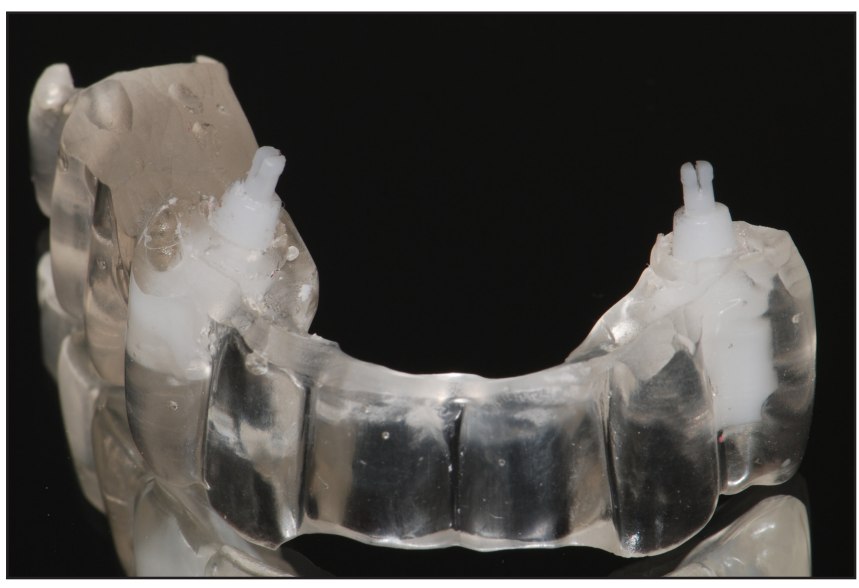

Figure 9. Template fabricated with position aids.

As long as the successful implant rehabilitation relies on being restoration-driven, the precise design of surgical templates will continue to be a prerequisite for predictable results. The dentist who chooses to invest in diagnosis, planning and construction of the surgical template will be redeemed with similar success in the final restoration and patient satisfaction [9]. There is not a single template design that fulfils the requirements of all treatment plans and clinical cases. In general, each surgical guide reflects a rational combination of basic prosthetic rules, the individual prosthetic needs and the surgeon's preference. It should be mentioned that the application of various types of surgical templates that are used in routine dental practice, require a certain learning curve in order to ensure maximum effectiveness.

\section{CONCLUSIONS}

The staged approach enables a smooth transition to implant restorations in advanced clinical cases. Implant placement during sequential surgical phases can be enhanced utilizing surgical guides anchored in preexisting implants. The utilization of implant mounts presents a practical and cost-effective method for the fabrication of an implant-retained template in a simplified manner. The surgical guide's stable fixation ensures the accuracy in implant positioning based upon the planned restoration.

\section{ACKNOWLEDGMENTS AND DISCLOSURE STATEMENTS}

The authors report no conflicts of interest related to this study. (page number not for citation purposes) 


\section{REFERENCES}

1. Zarb GA, Schmitt A. The longitudinal clinical effectiveness of osseointegrated dental implants: the Toronto Study. Part II: The prosthetic results. J Prosthet Dent. 1990 Jul;64(1):53-61. [Medline: 2200880] [doi: 10.1016/0022-3913(90)90153-4]

2. Romeo E, Chiapasco M, Ghisolfi M, Vogel G. Long-term clinical effectiveness of oral implants in the treatment of partial edentulism. Seven-year life table analysis of a prospective study with ITI dental implants system used for single-tooth restorations. Clin Oral Implants Res. 2002 Apr;13(2):133-43. [Medline: 11952733] [doi: 10.1034/j.1600-0501.2002.130203.x]

3. Garber DA. The esthetic dental implant: letting restoration be the guide. J Am Dent Assoc. 1995 Mar;126(3):319-25. [Medline: 7897100]

4. Chen ST, Buser D. Clinical and esthetic outcomes of implants placed in postextraction sites. Int J Oral Maxillofac Implants. 2009;24 Suppl:186-217. Review. [Medline: 19885446]

5. Jivraj S, Chee W. Transitioning patients from teeth to implants. Br Dent J. 2006 Dec 9;201(11):699-708. Review. [Medline: 17159950] [doi: 10.1038/sj.bdj.4814302]

6. Lazzara RJ. Effect of implant position on implant restoration design. J Esthet Dent. 1993;5(6):265-9. [Medline: 7993672] [doi: 10.1111/j.1708-8240.1993.tb00791.x]

7. Murrell GA, Davis WH. Presurgical prosthodontics. J Prosthet Dent. 1988 Apr;59(4):447-52. [Medline: 3283329] [doi: 10.1016/0022-3913(88)90040-6]

8. Greenstein G, Cavallaro J. The relationship between biologic concepts and fabrication of surgical guides for dental implant placement. Compend Contin Educ Dent. 2007 Apr;28(4):196-203; quiz 204. [Medline: 17487045$]$

9. Fortin T, Champleboux G, Lormée J, Coudert JL. Precise dental implant placement in bone using surgical guides in conjunction with medical imaging techniques. J Oral Implantol. 2000;26(4):300-3. [Medline: 11831236] [doi: 10.1563/1548-1336(2000)026<0300:PDIPIB >2.3.CO;2]

10. Adrian ED, Ivanhoe JR, Krantz WA. Trajectory surgical guide stent for implant placement. J Prosthet Dent. 1992 May;67(5):687-91. [Medline: 1527757] [doi: 10.1016/0022-3913(92)90172-7]

11. Higginbottom FL, Wilson TG Jr. Three-dimensional templates for placement of root-form dental implants: a technical note. Int J Oral Maxillofac Implants. 1996 Nov-Dec;11(6):787-93. [Medline: 8990642]

12. Basten $\mathrm{CH}$. The use of radiopaque templates for predictable implant placement. Quintessence Int. 1995 Sep;26(9):609-12. [Medline: $\underline{8602440]}$

13. Rosner O, Gross M, Nissan J. Use of a provisional restoration as a radiographic guide prior to implant placement. J Prosthet Dent. 2006 Oct;96(4):303-4. [Medline: 17052476] [doi: 10.1016/j.prosdent.2006.08.003]

14. Stellino G, Morgano SM, Imbelloni A. A dual-purpose, implant stent made from a provisional fixed partial denture. J Prosthet Dent. 1995 Aug;74(2):212-4. [Medline: 8537934] [doi: 10.1016/S0022-3913(05)80191-X]

15. Oh WS, Saglik B. Use of a thermoplastic vacuum-formed matrix for secure engagement of an implant surgical template. J Prosthet Dent. 2008 Oct;100(4):326-7. [Medline: 18922264] [doi: $10.1016 /$ S0022-3913(08)60219-X]

16. Sicilia A, Enrile FJ, Buitrago P, Zubizarreta J. Evaluation of the precision obtained with a fixed surgical template in the placement of implants for rehabilitation of the completely edentulous maxilla: a clinical report. Int J Oral Maxillofac Implants. 2000 Mar-Apr;15(2):272-7. [Medline: 10795461]

17. Holst S, Blatz MB, Wichmann M, Eitner S. Clinical application of surgical fixation screws in implant prosthodontics--Part I: positioning of radiographic and surgical templates. J Prosthet Dent. 2004 Oct;92(4):395-8. [Medline: 15507916] [doi: 10.1016/j.prosdent.2004.07.009]

18. Simon H. Use of transitional implants to support a surgical guide: enhancing the accuracy of implant placement. J Prosthet Dent. 2002 Feb;87(2):229-32. [Medline: 11854682] [doi: 10.1067/mpr.2002.121824]

19. Yeh S, Monaco EA, Buhite RJ. Using transitional implants as fixation screws to stabilize a surgical template for accurate implant placement: a clinical report. J Prosthet Dent. 2005 Jun;93(6):509-13. [Medline: 15942608] [doi: 10.1016/j. prosdent.2005.04.014]

20. Al-Harbi SA, Verrett RG. Fabrication of a stable surgical template using staged tooth extraction for immediate implant placement. J Prosthet Dent. 2005 Oct;94(4):394-7. [Medline: 16198179] [doi: 10.1016/j.prosdent.2005.08.003]

21. Weinberg LA, Kruger B. Three-dimensional guidance system for implant insertion: Part II. Dual axes table--problem solving. Implant Dent. 1999;8(3):255-64. [Medline: 10709472] [doi: 10.1097/00008505-199903000-00007]

22. Buser D, Martin W, Belser UC. Optimizing esthetics for implant restorations in the anterior maxilla: anatomic and surgical considerations. Int J Oral Maxillofac Implants. 2004;19 Suppl:43-61. [Medline: 15635945]

23. Sadan A, Raigrodski AJ, Salinas TJ. Prosthetic considerations in the fabrication of surgical stents for implant placement. Pract Periodontics Aesthet Dent. 1997 Nov-Dec;9(9):1003-11; quiz 1012. Review. [Medline: 9573853] 


\section{To cite this article:}

Patras M, Martin W, Sykaras N. A Novel Surgical Template Design in Staged Dental Implant Rehabilitations.

J Oral Maxillofac Res 2012;3(2):e5

URL: http://www.ejomr.org/JOMR/archives/2012/2/e5/v3n2e5ht.pdf

doi: $10.5037 /$ jomr.2012.3205

Copyright (C) Patras M, Martin W, Sykaras N. Accepted for publication in the JOURNAL OF ORAL \& MAXILLOFACIAL RESEARCH (http://www.ejomr.org), 22 May 2012

This is an open-access article, first published in the JOURNAL OF ORAL \& MAXILLOFACIAL RESEARCH, distributed under the terms of the Creative Commons Attribution-Noncommercial-No Derivative Works 3.0 Unported License, which permits unrestricted non-commercial use, distribution, and reproduction in any medium, provided the original work and is properly cited. The copyright, license information and link to the original publication on (http://www.ejomr.org) must be included. 